\title{
The world of krypton revisited
}

\begin{abstract}
Matic Lozinšek and Gary J. Schrobilgen consider krypton - namesake of Superman's home planet its superoxidant compounds, and their roles in coaxing elements into their highest oxidation states.
\end{abstract}

Element 36 takes its name from the Greek word, kryptos meaning hidden. Like all other members of group 18 (the noble gases), it is colourless, odourless, and occurs in only minute amounts in the Earth's atmosphere (1.14 ppm in dry air). It was Sir William Ramsay who, following the 1894 discovery of argon with Lord Rayleigh, suggested that a new family of elements would now need to be accommodated within the periodic table. In 1898 Ramsay, together with Morris Travers, went on to discover krypton, and two weeks later neon and xenon in residues remaining after evaporating nearly all components of liquid air.

Krypton gas is commercially produced by fractional distillation of liquefied air. Its only other notable source is uranium fission from nuclear reactors. It produces ${ }^{85} \mathrm{Kr}$ (fission yield $\sim 0.3 \%$ ), a radioisotope with a half-life of 10.8 years, which decays into non-radioactive ${ }^{85} \mathrm{Rb}$, and which has been used to detect clandestine military-based nuclear activities.

For a time (1960-1983), the metre was defined as 1,650,763.73 wavelengths of the red-orange $(605 \mathrm{~nm})$ emission line of ${ }^{86} \mathrm{Kr}$. Element 36 serves in high-performance incandescent light bulbs to retard the evaporation of the tungsten filament, improving efficiency and enhancing the brightness and lifetime of the bulb although these are now being superseded by LED technology. The krypton-fluoride laser, a type of excimer or exciplex (excited complex) laser, is widely employed in photolithography, which has enabled further miniaturization of semiconductor devices and an increase in their densities on silicon chips. In addition to its lighter noble-gas neighbour argon, krypton may also be found in homes where it serves as a highefficiency thermal insulator in double- or triple-pane glass windows. Liquid krypton electromagnetic calorimeters employed in particle physics research hold up to $\sim 30$ tonnes of krypton and are the largest known concentrations of this rare gas.

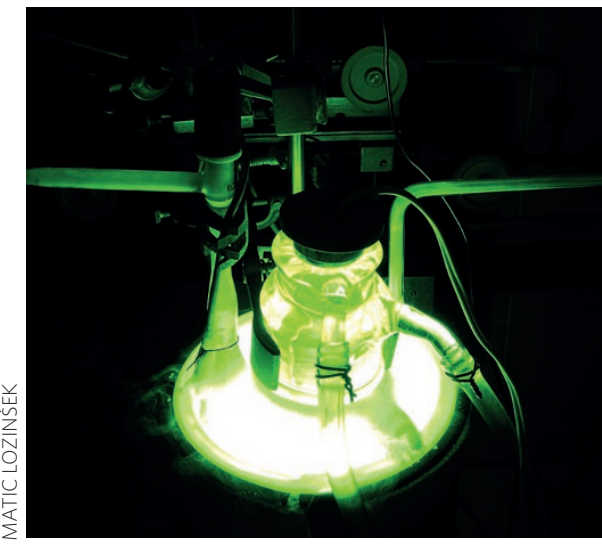

Synthesis of $\mathrm{KrF}_{2}$ by UV-irradiation of liquid- $\mathrm{N}_{2}$ cooled solid $\mathrm{Kr}$ and liquid $\mathrm{F}_{2}$ with a Hg lamp.

Krypton is the lightest noble gas to form compounds that are isolable in macroscopic amounts. The synthesis and isolation of the first krypton compound, $\mathrm{KrF}_{2}$, was reported in 1963 shortly after the syntheses of the first xenon compounds in $1962-65$ years after the discovery of these noble gases ${ }^{1,2}-$ although unfortunately at the time it was erroneously described as $\mathrm{KrF}_{4}$ instead ${ }^{1}$. Krypton difluoride has so far remained the only isolated binary krypton compound. Unlike xenon compounds, which have been characterized for xenon in the $+1 / 2,+2$, $+4,+6$, and +8 oxidation states, krypton chemistry is limited to the +2 oxidation state and all known compounds have been derived from $\mathrm{KrF}_{2}$ (ref. 3).

Owing to its thermodynamic instability, $\mathrm{KrF}_{2}$ is a better source of $\mathrm{F}^{*}$ radicals and a much stronger oxidizer than elemental fluorine, $\mathrm{F}_{2}$. Its synthesis in gram quantities is challenging and only a few low-temperature methods $s^{3}$ based on the generation of $\mathrm{F}^{*}$ radicals are in use, such as hot wire, electric glow discharge, and UV photolysis (pictured) methods. Derivatives of $\mathrm{KrF}_{2}$ are often prepared by utilizing its fluoride-ion donor abilities, which in reaction with strong Lewis acids such as $\mathrm{SbF}_{5}$ or $\mathrm{AsF}_{5}$, forms salts of the $\mathrm{KrF}^{+}$and $\mathrm{Kr}_{2} \mathrm{~F}_{3}{ }^{+}$cations ${ }^{4}$. With weak fluoride acceptors, $\mathrm{KrF}_{2}$ forms fluoride-bridged adducts where the $\mathrm{KrF}_{2}$ ligand coordinates through fluorine to either metal or non-metal centres, for example $\mathrm{MOF}_{4}(\mathrm{M}=\mathrm{Cr}, \mathrm{Mo}, \mathrm{W})$ and $\mathrm{BrOF}_{2}^{+}$. The Lewis acidity of the $\mathrm{KrF}^{+}$ cation has been exploited for the synthesis of $[\mathrm{HCNKrF}]^{+}\left[\mathrm{AsF}_{6}\right]^{-}$, which features the first example of a krypton-nitrogen bond ${ }^{5}$. Krypton is, however, rather selective in its choice of bonding partners and will only bond under the right conditions to the most electronegative atoms - fluorine, oxygen, and nitrogen - with only one example of a $\mathrm{Kr}-\mathrm{O}$ bond known thus far, in $\mathrm{Kr}\left(\mathrm{OTeF}_{5}\right)_{2}$.

The extreme oxidizing abilities of $\mathrm{KrF}_{2}$ and $\mathrm{KrF}^{+}$have been exploited for the syntheses of otherwise hard-to-attain high-valent compounds containing Ag(III), $\mathrm{Ni}(\mathrm{IV}), \mathrm{Au}(\mathrm{v})$, and exotic species such as $\mathrm{Tc}^{\mathrm{VII}} \mathrm{OF}_{5}, \mathrm{Os}^{\mathrm{VIII}} \mathrm{O}_{2} \mathrm{~F}_{4}, \mathrm{Cl}^{\mathrm{VII}} \mathrm{F}_{6}{ }^{+}$, and $\mathrm{Br}^{\mathrm{VII}} \mathrm{F}_{6}{ }^{+}$. These applications demonstrate that the original krypton compound, $\mathrm{KrF}_{2}$, is not simply a chemical curiosity in the scientific cabinet of wonders but also a part of the chemist's toolbox.

In 1938, the name of this element inspired the naming of Krypton, Superman's birth planet, as well as the powerful material originating from this planet called kryptonite. The analogy between the 'superoxidants' $\mathrm{KrF}_{2}, \mathrm{KrF}^{+}$, and $\mathrm{Kr}_{2} \mathrm{~F}_{3}{ }^{+}$, which rob other strong oxidant species of their electrons, and kryptonite, which robs Superman of his powers, is, of course, pure coincidence.

References

1. Grosse, A. V., Kirshenbaum, A. D., Streng, A. G. \& Streng, L. V. Science 139, 1047-1048 (1963).

2. Schreiner, F., Malm, J. G. \& Hindman. J. C. J. Am. Chem. Soc. 87, 25-28 (1965).

3. Lehmann, J. F., Mercier, H. P. A. \& Schrobilgen, G. J. Coord. Chem. Rev. 233-234, 1-39 (2002).

4. Lehmann, J. F., Dixon, D. A. \& Schrobilgen, G. J. Inorg. Chem. 40, 3002-3017 (2001).

5. Schrobilgen, G. J. J. Chem. Soc. Chem. Commun. 863-865 (1988).

\section{GARY J. SCHROBILGEN and}

MATIC LOZINŠEK are in the Department of Chemistry, McMaster University, Hamilton, Ontario L8S 4M1, Canada.

e-mail:schrobil@mcmaster.ca; matic.lozinsek@gmail.com 